\title{
Assessing reproductive resilience: an example with South Atlantic red snapper Lutjanus campechanus
}

\author{
Susan Lowerre-Barbieri ${ }^{1, *}$, Laura Crabtree ${ }^{1}$, Theodore Switzer $^{1}$, \\ Sarah Walters Burnsed ${ }^{1}$, Cameron Guenther ${ }^{1,2}$ \\ ${ }^{1}$ Florida Fish and Wildlife Conservation Commission, Florida Fish and Wildlife Research Institute, 100 Eighth Avenue S.E., \\ St. Petersburg, Florida 33701-5020, USA \\ ${ }^{2}$ Present address: 3818 Turkey Oak Drive, Valrico, Florida 33596, USA
}

\begin{abstract}
We developed a conceptual model of reproductive resilience based on spatio-temporal diversity in spawning activity and the 'big old fat fecund female fish' effect, i.e., trends in reproductive traits with size and age. We chose red snapper Lutjanus campechanus as our case study, as this species is highly fecund, currently overfished, and long-lived $(50+\mathrm{yr})$. The intrinsic reproductive resilience of red snapper was assessed in terms of spawning site distribution, variability in time of spawning, and potential reproductive lifespan. To assess how age truncation might erode reproductive resilience, we evaluated the strength of the relationship between size and age and the following traits: spawning habitat, reproductive timing, batch fecundity, and egg quality. Few fish were older than $7 \mathrm{yr}$. Although younger fish occurred in a more restricted range of depths, there was no trend between size or age and depth. Spawning activity was well distributed over space and time, with actively spawning females collected at 92 of 195 sampling sites over an extended spawning season. Larger, older females exhibited longer spawning periods and higher batch fecundities, but neither greater spawning frequency nor egg dry weight. The ratio of the effective to predicted reproductive lifespan at maximum sustainable yield was $31 \%$. Many parameters estimated in this study are common to fish reproductive studies, but we hope that integrating them into a reproductive resilience framework will help focus the need for research on the underlying relationships between reproductive traits and stock productivity.
\end{abstract}

KEY WORDS: Spawning $\cdot$ BOFFFF $\cdot$ Fisheries management $\cdot$ Spatio-temporal diversity $\cdot$ Age truncation - Maturation - Maternal effects - Spawner-recruit relationship - Reproductive success

\section{INTRODUCTION}

Resilience is defined as 'the capacity of a system to absorb disturbance and reorganize while undergoing change so as to still retain essentially the same function, structure, identity, and feedback loops' (Walker et al. 2004, p. 2). This definition of resilience is being increasingly integrated into ecology, conservation, and ecosystem-based management (Hughes et al. 2005, Folke 2006, Healey 2009). However, in marine fish stock assessments, resilience is measured as the steepness $(h)$ or the slope of the stock-recruitment curve near the origin (Myers et al. 1999, Mangel et al.

\footnotetext{
${ }^{*}$ Corresponding author: susan.barbieri@myfwc.com
}

2013). Although this is a useful measure, it measures only 1 component of a reproductive strategy, i.e. the correlation between abundance (typically measured by spawning stock biomass, SSB) or reproductive output (measured by egg production) and survival of that output. Most exploited marine fishes are highly fecund (Murua \& Saborido-Rey 2003) and can produce large year classes even at reduced levels of

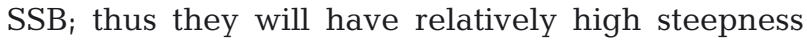
and would be considered 'resilient' by this measure. However, highly fecund marine fish can be overfished and are not immune to extinction risk (Sadovy 2001, Sadovy de Mitcheson et al. 2013), suggesting a

(C) The authors 2015. Open Access under Creative Commons by Attribution Licence. Use, distribution and reproduction are unrestricted. Authors and original publication must be credited. 
need to integrate additional information on a stock's reproductive potential into our stock assessments (Mangel et al. 2013).

Reproductive strategies are complex, adaptable systems that evolved under a given regime of natural mortality (Young et al. 2006, Lowerre-Barbieri et al. 2011a). Highly fecund marine species differ in a range of reproductive traits, including maturity and longevity, gender and mating systems, spatial attributes (e.g. spawning migrations, spawning site selection, and fidelity), and the temporal pattern of reproduction over a lifetime or reproductive timing (Lowerre-Barbieri et al. 2011b). Adaptations to offset natural mortality have led to the selection of these traits; that is, regardless of extremely high fecundity and low larval survival rates, certain adult traits have resulted in greater reproductive success in a given habitat. A species' reproductive compensatory ability depends on the selection pressures under which it evolved (Garrod \& Horwood 1984); thus, developing the means to quantify reproductive resilience to fishing and other stressors will improve our predictions of marine fish population growth.

Canale et al. (2012, p. 1) defined reproductive resilience as 'the ability to maintain a constant reproductive output despite unexpected environmental disturbances'. Here, we expand upon this definition (which was applied to small primates) to encompass elements specific to marine fish reproductive strategies. Specifically, we define reproductive resilience as the reproductive capacity of a population to maintain the level of reproductive success needed to result in long-term population stability despite disturbances such as environmental perturbations and fishing. Reproductive success refers to the probability that offspring will survive to reproductive age, and it will be impacted by both reproductive output and factors affecting the survival rate of that output (LowerreBarbieri 2009). Our conceptual model assumes that reproductive resilience in marine fishes increases with increased diversity in spatio-temporal spawning behavior, given the importance of these factors to reproductive success (Begg \& Marteinsdottir 2002, Rowe \& Hutchings 2003). Further, it assumes that reproductive resilience, especially to fishing, is affected by the relationship between size and/or age and a range of reproductive traits (Fig. 1). This is based on the increased recognition of the value of big old fat fecund female fish (BOFFFFs) to stock productivity (Hixon et al. 2014) in terms of increased annual fecundity (Fitzhugh et al. 2012, Cooper et al. 2013), spatio-temporal reproductive behavior (Scott et al. 2006, Anderson et al. 2008), energy reserves (Jør-
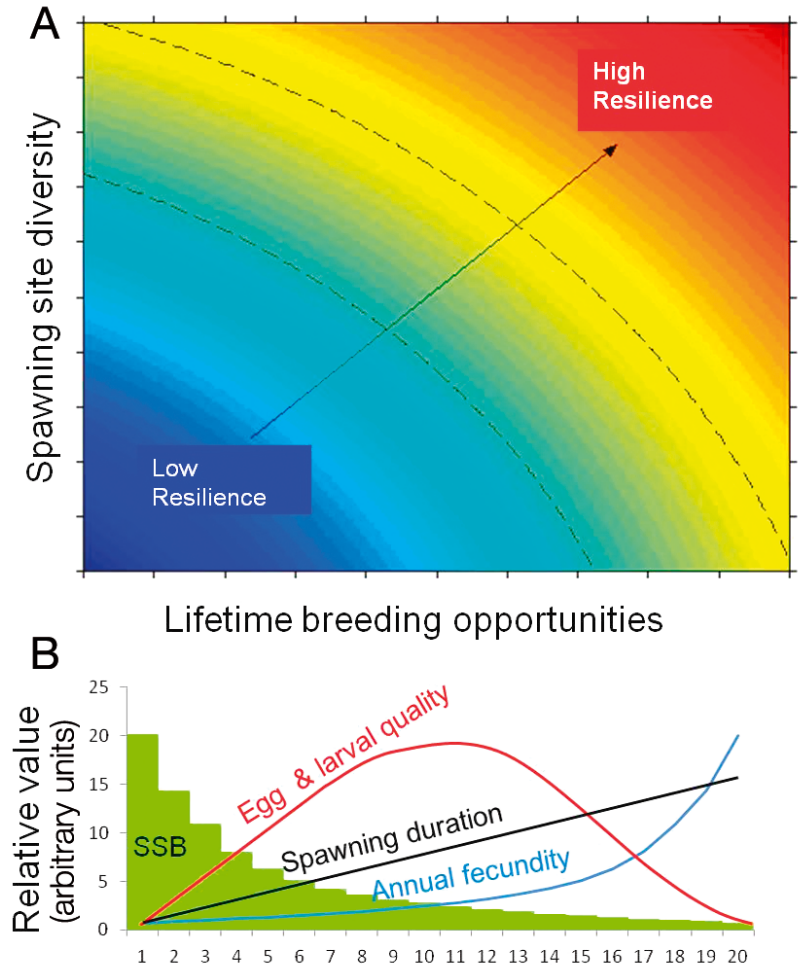

Age (yr)

Fig. 1. (A) Conceptual model of reproductive resilience based on spatio-temporal diversity. Dashed curves show how a given resilience level can be met through tradeoffs between spatial and temporal diversity. (B) Potential relationships with age of reproductive traits impacting reproductive success: spawning stock biomass (SSB; a proxy for abundance), annual fecundity (blue), spawning duration as a proxy for the distribution of spawning events within a spawning season (black), and the maternal effects on egg and larval quality (red)

gensen et al. 2006, Rideout \& Tomkiewicz 2011), and their impact on both the number of spawning events and how they are distributed over the spawning season (Wright \& Trippel 2009), as well as egg and larval quality (Kamler 2005). In addition, reproductive lifespan is an important component of reproductive resilience, as it determines the number of years over which an individual fish potentially can spawn and thus the ability for older, larger fish to outlive periods of poor recruitment. However, we propose that the BOFFFF effect can apply to any reproductive trait which results in a relationship between reproductive success and fish age or size, regardless of sex.

We chose red snapper Lutjanus campechanus as our case study given that this species is highly fecund, is currently considered overfished, and is recognized for having high compensatory reserve, i.e. resilience (Rose et al. 2001). Red snapper support important commercial and recreational fisheries in 
the Gulf of Mexico and the southeastern USA, with both the Gulf and South Atlantic (SA) stocks exhibiting highly truncated age distributions (Cowan 2011). The latest benchmark assessment (SEDAR24 2010) indicated that the SA red snapper stock was both overfished and undergoing overfishing, but also documented a sharp increase in abundance due to recent high recruitment in 2006 and 2007. Red snapper are long-lived, with a maximum reported age of 54 yr (SEDAR24 2010), and are highly fecund, with indeterminate fecundity and an extended spawning season (Collins et al. 1996, Woods et al. 2003, BrownPeterson et al. 2009, Brulé et al. 2010).

In this study, we evaluated the reproductive resilience of the SA red snapper stock at the species scale (i.e. the underlying reproductive strategy) and in the current overfished stock. Red snapper reproductive resilience was assessed in terms of potential reproductive lifespan (i.e. that expected in a virgin stock) and within-population diversity in spatio-temporal reproductive behavior. To assess how age truncation might erode reproductive capacity, we evaluated the strength of the relationship between reproductive behavior and demographics, or the BOFFF effect, for the following reproductive traits: spawning habitat, reproductive timing, batch fecundity, and egg dry weight. To quantify the extent of age truncation, we calculated the ratio of current to potential reproductive lifespan as well as the effective reproductive lifespan based on the 90th percentile of the sampled age distribution and that expected for the stock at maximum sustainable yield (MSY). The following specific hypotheses were tested within the above context: (1) spawning fish would aggregate in large numbers at relatively few spawning sites; (2) the time of spawning events would exhibit diel periodicity; (3) females would mature younger and smaller than predicted based on growth dynamics; (4) spawning seasonality and activity would differ with size and/or age; and (5) batch fecundity and egg quality, as measured by egg dry weight, would exhibit a significant increase with both size and age.

\section{MATERIALS AND METHODS}

\section{Sample collections}

The sampling area corresponded to the center of the SA red snapper population, off the east coast of Florida (Fig. 2), from roughly 28 00' N (Melbourne, Florida) to $30^{\circ} 45^{\prime} \mathrm{N}$ (White \& Palmer 2004). The sample area was subdivided every $1^{\circ}$ of latitude to create sampling zones which corresponded to National Marine Fisheries Service (NMFS) statistical reporting zones: 722, 728, and 732. Presumed suitable hard-bottom habitat locations were obtained from participating fishers (commercial and recreational), federal agency partners (i.e. NMFS, US Geological Service), and Florida Fish and Wildlife Commission's historical data. A sampling universe was built around these locations, with primary sampling units delineated as 0.3 nautical miles ( $\mathrm{n}$ miles) latitude by $0.1 \mathrm{n}$ miles longitude grids containing reef habitat. Sampling sites were randomly selected from the universe, and sampling effort was stratified by sampling zone and depth

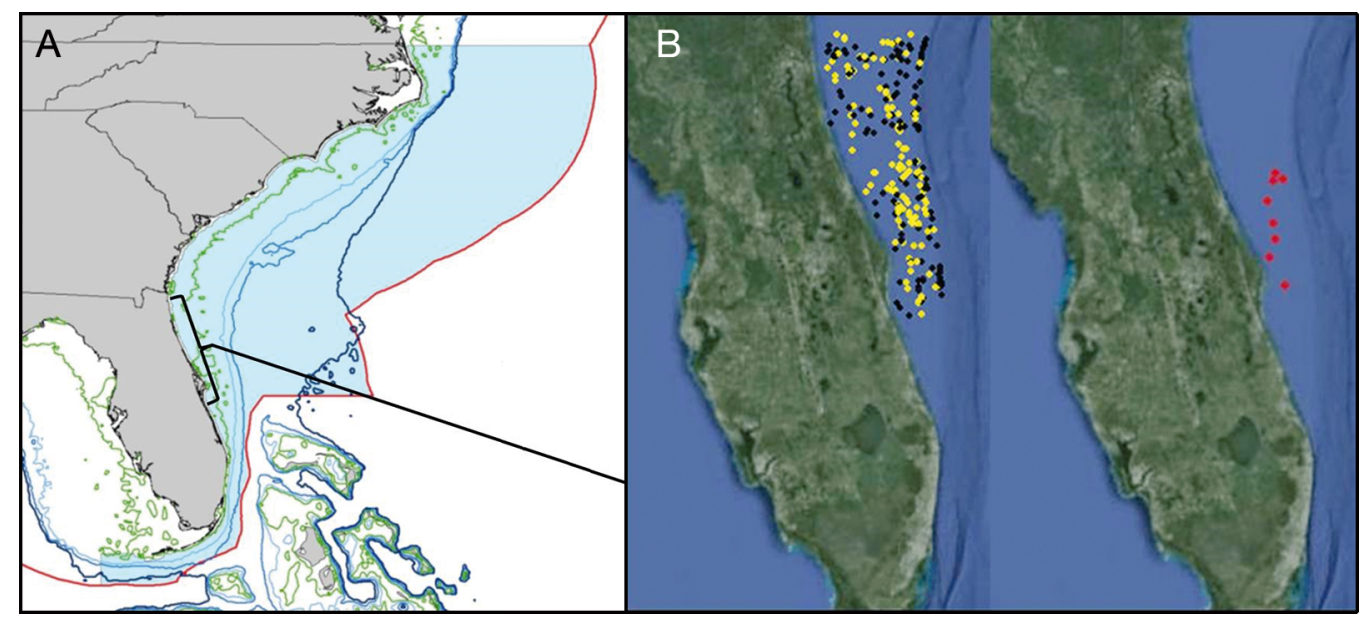

Fig. 2. (A) Spatial distribution of the management zone for South Atlantic red snapper Lutjanus campechanus (area filled in blue), and depth contours: $20 \mathrm{~m}$ (green) $200 \mathrm{~m}$ (light blue), $500 \mathrm{~m}$ (medium blue), $1000 \mathrm{~m}$ (dark blue), and the US exclusive economic zone (red). (B) left panel: the study site with red snapper sampling sites (black dots) and locations where red snapper were caught (yellow dots); right panel: spatial distribution of key spawning sites with $>20 \%$ spawning fraction and $>10$ females sampled per date (red dots) 
(inshore, inside the $30 \mathrm{~m}$ isobath; offshore, between the 30 and $100 \mathrm{~m}$ isobaths). For inshore strata, 12 sites were selected per zone each month. In an effort to preserve the proportionality of sampling to available habitat throughout the sampling universe, 20 sites were selected per zone each month for offshore strata. At each site, date, time (Eastern Standard Time), depth, and latitude and longitude were recorded.

Monthly hooked-gear surveys were conducted from April through October. The study was initially designed to occur over a 4 mo period (April to July), but poor weather conditions resulted in lower than expected sampling effort in this time period. Sampling was extended through October, and the sampling design was adjusted to select more stations from the sampling zones and strata that were undersampled during the initial period (Table 1). From April through August, there was an average of 13 sampling dates per month (range: 10-14), with less effort in September and October (4 and 3 sampling dates, respectively).

Fishing methods and effort were standardized at all sampling sites. Three sampling techniques were used (passively fished vertical and horizontal bottom long lines and an actively fished repetitive timed drop method using Elec-tra-mate ${ }^{\complement}$ gear), but $88 \%$ of the samples $(\mathrm{n}=1157$ ) came from the active repetitive timed drop method. All hooks were baited with Atlantic mackerel Scomber scombrus cut proportional to hook size. In certain conditions (e.g. rough seas, extreme currents), it was necessary to use the motor to maintain the boat over the intended site. For each sampling site, the bottom long line was fished at least $0.1 \mathrm{n}$ miles away from the other gears. If there was not enough suitable habitat at a site to sample all gears, priority was given to the active fishing and vertical long line gears. Neither long line was

Table 1. Summary of sites selected (with number of sites sampled in parentheses) for red snapper Lutjanus campechanus, according to National Marine Fisheries Service statistical zone and depth stratum (shallow: <30 m, deep: >30 m)

\begin{tabular}{|cccccccc|}
\hline \multirow{2}{*}{ Zone } & Depth stratum & April & May & June & July & August & Sept./Oct. \\
\hline 722 & Shallow & $12(10)$ & $12(11)$ & $12(11)$ & $12(8)$ & $6(3)$ & $10(6)$ \\
& Deep & $20(16)$ & $20(11)$ & $20(5)$ & $20(17)$ & $24(12)$ & $16(11)$ \\
728 & Shallow & $12(12)$ & $12(12)$ & $12(6)$ & $12(12)$ & $6(5)$ & $10(4)$ \\
& Deep & $20(16)$ & $20(19)$ & $20(8)$ & $20(20)$ & $20(9)$ & $8(0)$ \\
732 & Shallow & $12(2)$ & $12(11)$ & $12(8)$ & $12(10)$ & $18(15)$ & $10(6)$ \\
& Deep & $20(20)$ & $20(12)$ & $20(4)$ & $20(14)$ & $25(9)$ & $16(9)$ \\
& Total & $96(76)$ & $96(76)$ & $96(42)$ & $96(81)$ & $99(53)$ & $70(36)$ \\
\hline
\end{tabular}

deployed if the current exceeded 2 knots, due to gear drift.

Because hook-and-line sampling can be biased due to angler experience or hook size, efforts were made to minimize these effects. Four anglers participated in active fishing, each assigned to a different rig type, with assignments rotated at each sampling site. Each rig consisted of a 2-hook combination (top hook listed first): $8 / 0$ and $11 / 0,8 / 0$ and $15 / 0$, or $11 / 0$ and 15/0 size hooks. At inshore sites, 2 rigs with the smallest hook combination were used, and at offshore sites, 2 rigs with the largest hook combination were used. We targeted 12 'team drops' per site in the inshore depth strata and 10 in offshore strata, as sampling at these sites took longer due to more difficult fishing conditions.

\section{Sample processing}

Fish were kept on ice until processed in the laboratory, generally within $24 \mathrm{~h}$ of capture. Each fish was measured for maximum total length ( $\mathrm{TL}, \pm 1 \mathrm{~mm}$ ) and total weight ( $T W, \pm 1 \mathrm{~g}$ ). For hydrated females, used to assess batch fecundity, gonad weight (GW) was measured and somatic weight (SW) calculated as TW GW. Sex was determined macroscopically, both sagittal otoliths were removed and stored dry, and ovarian tissue samples were taken for histological analysis. A section of ovarian tissue was processed for histological analysis as follows: fixed in $10 \%$ neutrally buffered formalin for a minimum of $24 \mathrm{~h}$, soaked in water for $1-2 \mathrm{~h}$, and stored in $70 \%$ ethanol. Samples were embedded in glycol methacrylate, sectioned to 3-5 mm thickness, stained with periodic acid-Schiff's hematoxylin, and then counterstained with metanil yellow (Quintero-Hunter et al. 1991).

Samples for gravimetric estimation of batch fecundity using the hydrated oocyte method (Hunter et al. 1985, Murua et al. 2003) were processed following LowerreBarbieri \& Barbieri (1993). Fresh oocytes were hydraulically separated from each other and from the ovarian membrane and preserved in $2 \%$ neutrally buffered formalin. Settling bias was reduced by stirring the samples, and then 2 subsamples $(\sim 0.1 \mathrm{~g})$ were removed and the number of hydrated oocytes counted. Estimates of batch fecundity were not used if histological 
analysis indicated that ovulation had begun (i.e. fresh postovulatory follicles [POFs] were present).

Hydrated oocyte dry weights were measured as a potential indicator of egg quality. Two replicates of 100 hydrated oocytes were selected from the samples used for batch fecundity, manually separated, and dried for $48 \mathrm{~h}$ at $68^{\circ} \mathrm{C}$. We recognize that formalinpreserved samples are not ideal (Haslob et al. 2013), but because all samples were preserved over a similar time period, we considered it adequate for our objective of comparing differences with size and age.

\section{Gonadal analysis}

Histological indicators used to assess reproductive state and phase (Table 2) followed Lowerre-Barbieri et al. (2009) and Brown-Peterson et al. (2011), with the slight modification that the most advanced oocyte stage in the developing phase was early vitellogenic (i.e. Vtg1). Five oocyte developmental stages were identified: primary growth (PG), cortical alveoli (CA), early vitellogenic (Vtg1), late vitellogenic (Vtg2 and Vtg3), and oocyte maturation (OM). The following characteristics of OM were noted: germinal vesicle migration (GVM), germinal vesicle breakdown (GVBD), yolk coalescence or clarification, and oocyte hydration (Jalabert 2005). Early OM oocytes had only slightly displaced germinal vesicles and little yolk coalescence or hydration, and these fish were expected to spawn within 5 to $14 \mathrm{~h}$ (Jackson et al. 2006). Late OM was characterized by completed GVM or GVBD, yolk coalescence, and hydrated oocytes detectable by macroscopic inspection, i.e. the increase in size and clarity due to hydration made them easily distinguished from yolked oocytes (Lowerre-Barbieri et al. 2009). POFs were classified as (1) fresh (i.e. newly collapsed, recognizable by the size and appearance of the granulosa cells' nuclei), (2) less than $24 \mathrm{~h}$, or (3) older than $24 \mathrm{~h}$ based on POF size and organization and time of capture (Hunter \& Macewicz 1985). The spawning-capable phase indicated

Table 2. Ovarian classification and terms based on histological analysis of red snapper Lutjanus campechanus. POF: postovulatory follicle, OM: oocyte maturation, GVM: germinal vesicle migration, GVBD: germinal vesicle breakdown

\begin{tabular}{|c|c|c|c|}
\hline Reproductive state & Phase & Histological indicators & Significance \\
\hline \multicolumn{4}{|l|}{ Immature } \\
\hline Non-spawning & Immature & $\begin{array}{l}\text { Only oogonia and primary growth } \\
\text { oocytes, including chromatin } \\
\text { nucleolar and perinucleolar oocytes. } \\
\text { Usually no atresia. }\end{array}$ & $\begin{array}{l}\text { Virgin that has not yet recruited to the } \\
\text { spawning population. }\end{array}$ \\
\hline \multicolumn{4}{|c|}{ (7) } \\
\hline Non-spawning & Developing & $\begin{array}{l}\text { Cortical alveolar and early vitello- } \\
\text { genic oocytes (Vtg1). No evidence } \\
\text { of POFs. Some atresia may be present. }\end{array}$ & $\begin{array}{l}\text { Environmental signals have triggered } \\
\text { development, but fish are not yet } \\
\text { developed enough to spawn. }\end{array}$ \\
\hline \multicolumn{4}{|c|}{ Spawning population } \\
\hline \multirow[t]{5}{*}{ Spawning-capable } & Spawning-capable & $\begin{array}{l}\text { Late vitellogenic oocytes (Vtg2 \& } 3 \text { ). } \\
\text { May be atresia. }\end{array}$ & Fish developed enough to spawn. \\
\hline & Subphase spawning & Oocyte maturation, hydration, or POFs. & Fish with indicators of spawning activity \\
\hline & Imminent & $\begin{array}{l}\text { Early OM (GVM with little yolk } \\
\text { coalescence) }\end{array}$ & Will spawn in $14 \mathrm{~h}$. \\
\hline & Active & $\begin{array}{l}\text { (1) Advanced GVM } \\
\text { (2) GVBD } \\
\text { (3) Hydrated or undergoing ovulation } \\
\text { (4) Newly-collapsed POFs }\end{array}$ & Spawning in $\pm 2 \mathrm{~h}$. \\
\hline & Recent & POFs $(12-36 \mathrm{~h}$ old $)$ & Spawned within $2 \mathrm{~d}$. \\
\hline \multicolumn{4}{|l|}{ Mature } \\
\hline Non-spawning & Regressing & $\begin{array}{l}\text { A high percentage of yolked oocytes } \\
\text { undergoing atresia (alpha and beta). }\end{array}$ & Cessation of spawning. \\
\hline Non-spawning & Regenerating & $\begin{array}{l}\text { Only primary growth oocytes present, } \\
\text { including chromatin nucleolar and } \\
\text { perinucleolar. Muscle bundles, } \\
\text { enlarged blood vessels, thick and/or } \\
\text { convoluted ovarian wall, and gamma } \\
\text { or delta atresia may be present. }\end{array}$ & $\begin{array}{l}\text { Sexually mature, reproductively } \\
\text { inactive. Most common outside of the } \\
\text { spawning season. }\end{array}$ \\
\hline
\end{tabular}


females sufficiently developed to spawn within days of receiving the appropriate endocrine signal (i.e. Vtg2 and Vtg3). Spawning females were those with either OM oocytes or POFs and actively spawning females were those with late OM, or fresh POFs.

Mature females were distinguished from immature females based on the following criteria: size of the ovarian cross section, ovarian wall thickness, lamellar structure and organization, and presence of muscle bundles (Lowerre-Barbieri et al. 2011b). In addition, immature females were assessed in terms of the development of their primary growth oocyte population, to determine whether they were capable of recruiting to the spawning population within the spawning season being sampled. Because there are no historical estimates of sexual maturity in SA red snapper, it was not possible to assess whether over-exploitation had impacted maturity schedules (Jørgensen et al. 2007, Heino et al. 2013). As a proxy for maturation in a virgin stock, we used 2 measures, (1) the Beverton-Holt life history invariant approach suggesting fish species mature at two-thirds their asymptotic length (Jensen 1996); and (2) and the mean maturation to asymptotic length ratio $(52 \%)$ reported for the subfamily Lutjaninae based on a literature review (Martinez-Andrade 2003). We used the asymptotic length of $902 \mathrm{~mm}$ TL (SEDAR24 2010).

Spawning activity was assessed at the annual scale to estimate the population spawning season and at the intraseasonal scale to estimate spawning fraction, interval, and frequency. The population spawning season was based on the first and last occurrence of spawning females. We used the definitions in LowerreBarbieri et al. (2011b) for spawning fraction, interval, and frequency. Spawning fraction was estimated both using the percent hydrated method and the POF method (Hunter \& Macewicz 1985, Murua et al. 2003). At the population scale, spawning interval was estimated as the reciprocal of the spawning fraction, and spawning frequency was estimated by dividing the number of days in the spawning season by spawning interval (Hunter \& Macewicz 1985, Murua et al. 2003). To assess demographic differences in spawning activity, the proportion of spawningcapable females with spawning indicators (both OM and POFs) was evaluated by age and TL classes.

\section{Otolith analysis}

Fish were aged using transverse sections of the sagittal otolith. Otoliths were sectioned through the core using a Buehler low-speed Isomet saw. Sections
350 to $500 \mu \mathrm{m}$ thick were mounted on glass slides with histomount. Sections which were difficult to read were also viewed in reflected light. All slides were read twice by 2 different readers and a third time if there were discrepancies. Percent agreement between all first and second reads was $95.2 \%$. Of the 63 discrepancies, $98.4 \%$ differed by a year, and the final age for these fish was determined based on a third read and consensus between the 2 readers. Ages were assigned to year classes by using a 1 January birthdate (Jearld 1983) to clearly separate fish born in different years.

\section{Age truncation}

Age truncation was assessed based on potential, observed, and predicted reproductive lifespan at MSY. Reproductive lifespan is the number of years an animal could be reproductively active (Stearns 1992). Changes in this parameter can be used to assess the effects of age truncation on reproductive capacity. Potential reproductive lifespan was used to refer to that expected in an unfished stock, and current reproductive lifespan refers to that observed in the sampled population. If senescence has not been indicated for the species being studied, reproductive lifespan is calculated as the maximum age minus age at maturity. The maximum age reported in the most recent stock assessment, 54 yr (SEDAR24 2010), was used to estimate potential reproductive lifespan. However, given the relationship between maximum age and sample size (Hoenig 1983), we also estimated the effective reproductive lifespan based on the maximum observed age at the 90th percentile and compared this to the maximum age at the 90th percentile estimated for the stock at MSY (SEDAR24 2010).

\section{Data analysis}

Before we could evaluate spatio-temporal patterns in reproductive effort, we needed to assess whether sex or gear type affected the size of fish sampled. Because size and age distributions did not meet the assumption of normality, we used nonparametric methods to compare size frequency distributions by sex (Kolmogorov-Smirnov, K-S test) and gear type (Kruskal-Wallis). We used quantile regression to assess overall range of ages sampled versus ranges sampled in each zone.

We evaluated the relationship between fish size and age and reproductive timing. To assess whether 
the probability of being spawning capable differed with size or age, we selected data from months with similar sampling effort (April through August) and grouped fish into 3 size categories: small $(<500 \mathrm{~mm}$ TL), medium (500 to $700 \mathrm{~mm}$ TL), and large (>700 mm $\mathrm{TL})$ and 3 age categories: young $(<$ age 4$)$, middle (ages 4 and 5), and older (> age 5). The proportion of females in the spawning population was modeled using a generalized linear model (PROC GENMOD in SAS), a binomial distribution, and a logit link function. A higher probability of being in the spawning population on the date of capture was assumed to be associated with a longer spawning period for fish in that size- or age-class (Lowerre-Barbieri et al. 2009). Females not in the spawning population were categorized as 0 and those in the spawning population as 1 . We used the same approach to evaluate demographic effects on the probability of spawning; however, in this analysis, we assessed the proportion of spawning females within the spawning population (LowerreBarbieri et al. 2009). Diel periodicity was evaluated by assessing hour of capture with histological indicators of imminent or active spawning. A non-parametric Kruskal-Wallis test was used to assess whether there was a relationship between spawn time and size or age. A bivariate kernel density estimation was used to evaluate the location with the highest density $(75 \%)$ of active spawners and to assess whether the spatial distribution of active spawners differed by size or age category.

Linear regression was used to model the basic relationship between batch fecundity and 2 measures of size (TL and SW). To linearize the parameters in the batch fecundity to SW and TL relationships, parameters were $\log _{\mathrm{e}}$-transformed. To assess whether zone or age significantly affected batch fecundity, stepwise linear regression was used to model the relationship between batch fecundity and the following main effects: TL, zone, and age. The significance level for variable inclusion was 0.5. All statistical analyses were performed using SAS version 9.13 and an alpha level of 0.05 .

\section{RESULTS}

\section{Sampled population}

A total of 1307 red snapper were aged, 1305 were sexed (722 females and 583 males), and ovarian samples were taken from 696 females for histological analysis. Similar numbers of red snapper were captured in the 2 most southern zones (Zones 732, n =
550; Zone $728, \mathrm{n}=524)$, with fewer captured in the northernmost zone (Zone 722, $\mathrm{n}=233$ ), although the oldest fish was sampled in this zone. Mean size was similar in the 2 northernmost zones (603 and $619 \mathrm{~mm}$ $\mathrm{TL}$, respectively), but smaller in the southernmost zone (527.8 mm TL). Fish $<350 \mathrm{~mm}$ TL were not fully recruited to any of the sampling sites, resulting in only 2 age- 1 fish being sampled. Fish size exhibited a bimodal pattern of abundance and ranged from 207 to $925 \mathrm{~mm}$ TL (Fig. 3). Size did not differ significantly with sex (K-S, $\left.\chi^{2}=1.27, \mathrm{p}=0.2596\right)$, or gear (KruskalWallis, $\chi^{2}=2.252, \mathrm{p}=0.2436$ ) but was clearly driven by several strong year-classes. Abundance was dominated by 2 yr olds $(16 \%, 2010$ year-class), 3 yr olds $(25 \%, 2009$ year-class $), 5$ yr olds $(29 \%, 2007$ yearclass), and 6 yr olds (13\%, 2006 year-class). In contrast, 4 yr olds made up only $5 \%$ of the sampled population. This drove the bimodal size distribution, with peaks in the $400-450 \mathrm{~mm}$ and the $650-700 \mathrm{~mm} \mathrm{TL}$ size classes.

Older, larger fish occurred in a wider range of depths but did not exhibit a significant trend with depth. Few fish (4\%) were sampled at depths greater than $60 \mathrm{~m}(\mathrm{n}=58)$, but all fish sampled at these deeper sites were $\geq 500 \mathrm{~mm}$ TL and older than age 3 (Fig. 3). However, larger, older fish also occurred in samples over a wide range of depths, and at the 0.9 quantile, size class did not differ significantly with depth of capture (quantile regression, $\chi^{2}=0.0, \mathrm{p}=$ $1.0, \mathrm{n}=1315$ ), nor did age (quantile regression, $\chi^{2}=$ $0.0, \mathrm{p}=1.0, \mathrm{n}=1305$ ).

\section{Spatio-temporal diversity in spawning}

Red snapper spawned throughout most of the study area, rather than concentrating spawning at a few highly populated sites (Fig. 4). The number of females collected at any given sample site (combination of date and location) exhibited a wide range $(0-19)$, as did the number of active spawners $(0-13)$. Although there were sites where multiple active spawners were sampled, the most common pattern was to collect only 1 active spawner per site (55\%, $\mathrm{n}=92$ sampling sites). Depth of sampling site did not differ significantly between active spawners and the remaining females (Kruskal Wallis, $\chi^{2}=1.4152, \mathrm{p}=$ $0.2342, \mathrm{n}=666$ ), with active spawners collected over a wide range of depths (15-73 m). Active spawners were sampled from 92 of the 195 unique sampling sites, and the sites with spawning females were distributed over a wide geographic range $\left(28.11^{\circ}-30.58^{\circ}\right.$ $\mathrm{N}$ to $81.02^{\circ}-80.05^{\circ} \mathrm{W}$ ), an area equal to $25502 \mathrm{~km}^{2}$. 


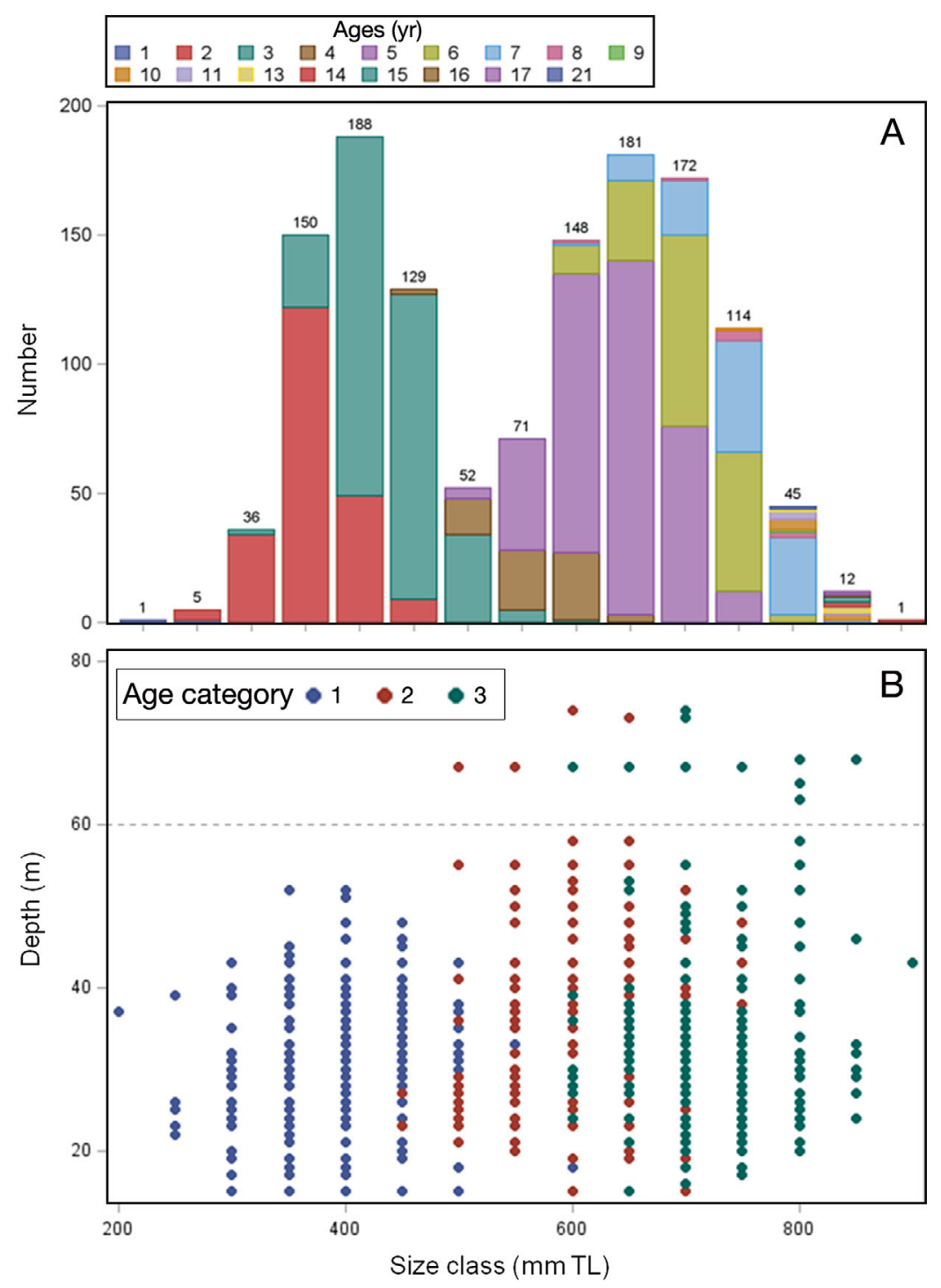

Fig. 3. (A) Size and age distribution of sampled red snapper Lutjanus campechanus. Size classes are based on $50 \mathrm{~mm}$ total length bins. (B) Distribution of age categories (1: 1-3 yr; $2: 4-5 \mathrm{yr} ; 3: \geq 6 \mathrm{yr})$ and size class by depth at capture

However, $75 \%$ of active spawners occurred within a much smaller area $\left(1183 \mathrm{~km}^{2}\right)$ bounded by $28.92^{\circ}$ to $29.58^{\circ} \mathrm{N}$ and $80.52^{\circ}$ to $80.35^{\circ} \mathrm{W}$. All age categories spawned in similar areas (Fig. 4), as did fish in different size categories.

Although red snapper spawning exhibited diel periodicity, some fish spawned throughout the day. Spawning indicators (OM substages and fresh POFs) differed significantly with hour (Kruskal Wallis, $\chi^{2}=$ 119.44, $\mathrm{p}<0.0001, \mathrm{n}=224$ ), and exhibited a general trend of later time associated with the expected progression in OM and ovulation (Fig. 5). However, those indicators associated with spawn times (hydrated oocytes and fresh POFs) occurred throughout the day, and there was no indication of a size (Kruskal Wallis, $\chi^{2}=17.4, \mathrm{p}=$ $0.0957, \mathrm{n}=115$ ) or age (Kruskal Wallis, $\chi^{2}=$ 8.6072, $\mathrm{p}=0.2821, \mathrm{n}=115$ ) effect on spawn time. Females with late OM were collected from 07:00 to $17: 00 \mathrm{~h}$ and 4 females with newly collapsed POFs were collected from 09:00 to 13:00 $\mathrm{h}$, indicating that at least some spawning occurred throughout the day.

\section{Maturity}

Virtually all of the females sampled in this study (99\%) were mature. Immature females $(\mathrm{n}=8)$, exhibited a wide size range (207$404 \mathrm{~mm}$ TL) but were young (age 2, $\mathrm{n}=7$; or age $1, n=1$ ) and mostly occurred in April and May ( $\mathrm{n}=7$ ). Immature females exhibited a range of development from a 1 yr old fish with no primary growth oocytes (Fig. 6A) to fish in the process of recruiting primary growth oocytes (Fig. 6B) and, further, to those with a fully-developed population of primary growth oocytes, capable of recruiting to the spawning population within the spawning season (Fig. 6C) similar to mature regenerating females (Fig. 6D). Based on Beverton-Holt life history invariants, the optimal size at maturation was predicted to be ca. $600 \mathrm{~mm}$ TL. Females in this size range (550 to $650 \mathrm{~mm} \mathrm{TL}, \mathrm{n}$ $=221$ ) had a mean age of $4.8 \mathrm{yr}$ (range: 3 to 8 yr). In contrast, the predicted length at maturation based on the size at maturation to size at asymptotic length relationship for the subfamily Lutjaninae was $469 \mathrm{~mm}$ TL. Females in this size range (400 to $500 \mathrm{~mm}$ TL) had a mean age of $2.82 \mathrm{yr}$ (range: 2 to $4 \mathrm{yr}, \mathrm{n}=319$ ).

Maturation and spawning capability at sizes and ages less than predicted was confirmed based on the prevalence of small mature femals (Fig. 6E) and on 30 age- 2 females $\leq 400 \mathrm{~mm}$ TL with histological indicators of spawning.

\section{Demographic trends in reproductive timing}

Spawning seasonality was asynchronous, with individual variability in spawning periods. Spawningcapable females occurred from April through September, and spawning females from 4 April to 20 September 2012, corresponding to $170 \mathrm{~d}$ in the popu- 

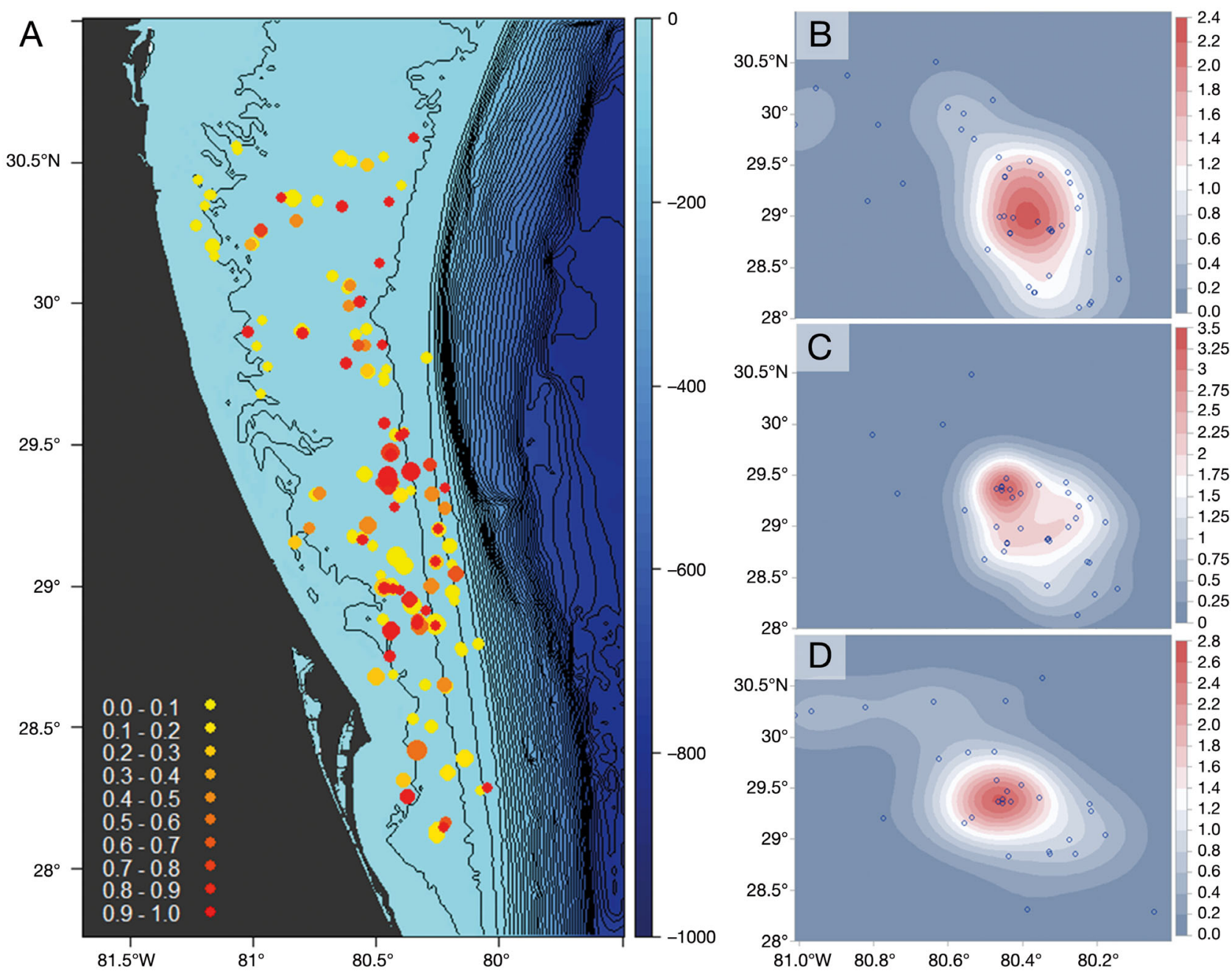

Fig. 4. (A) All sites where female red snapper Lutjanus campechanus were sampled. Bubble size represents the number of female red snapper caught (range 1 to 19) and color represents spawning fraction, with yellow representing the lowest spawning fraction and red the highest. Water depth is indicated by the color bar to the right. Also shown are kernel density estimates of active spawners by age category for ages (B) 2-3 yr, (C) $4-5 \mathrm{yr}$, and (D) $>5 \mathrm{yr}$. Relative densities of spawning females are indicated by the color bar to the right, with red indicating the areas with the highest densities

lation spawning season. However, the proportion of spawning-capable females differed significantly with month (binomial regression, $\mathrm{n}=679, \mathrm{p}<0.0001$ ) and age (binomial regression, $\mathrm{n}=679$, $\mathrm{p}<0.0001$ ), with older fish exhibiting a higher probability of being spawning capable in all months (Fig. 7A). A similar pattern was seen with size category (Fig 7B), with the proportion of spawning-capable females differing significantly with month (binomial regression, $\mathrm{n}=$ 679, $\mathrm{p}<0.0001$ ) and size category (Fig. 7B; binomial regression, $\mathrm{n}=679, \mathrm{p}<0.0001)$. In April, only $24 \%$ of small fish $(<500 \mathrm{~mm}$ TL) were spawning capable, compared to $76 \%$ of the large fish (>700 mm TL). Similarly, large fish continued to have a higher proportion of spawning-capable females in July and August than small fish.
Red snapper exhibited high spawning activity, with an overall spawning fraction of $32.7 \%$ for the hydrated method and $17.6 \%$ for Day 1 POFs. Using traditional methods to assess spawning interval, these percentages correspond to 1 spawn approximately every $3 \mathrm{~d}$ (\% hydrated) or once every $5.7 \mathrm{~d}$ (POF). The annual spawning frequency thus was higher for the percent hydrated method, viz. 57 spawns, compared to approximately 30 based on the POF method. However, spawning activity was not evenly distributed throughout the spawning season, exhibiting a clear maximum in June (Fig. 8). The proportion of spawning-capable females that had spawning indicators differed significantly by month (binomial regression, $\mathrm{n}=558, \mathrm{p}<0.001$ ), but not by size $(p=0.9801)$ or age $(p=0.5787)$, ranging from 


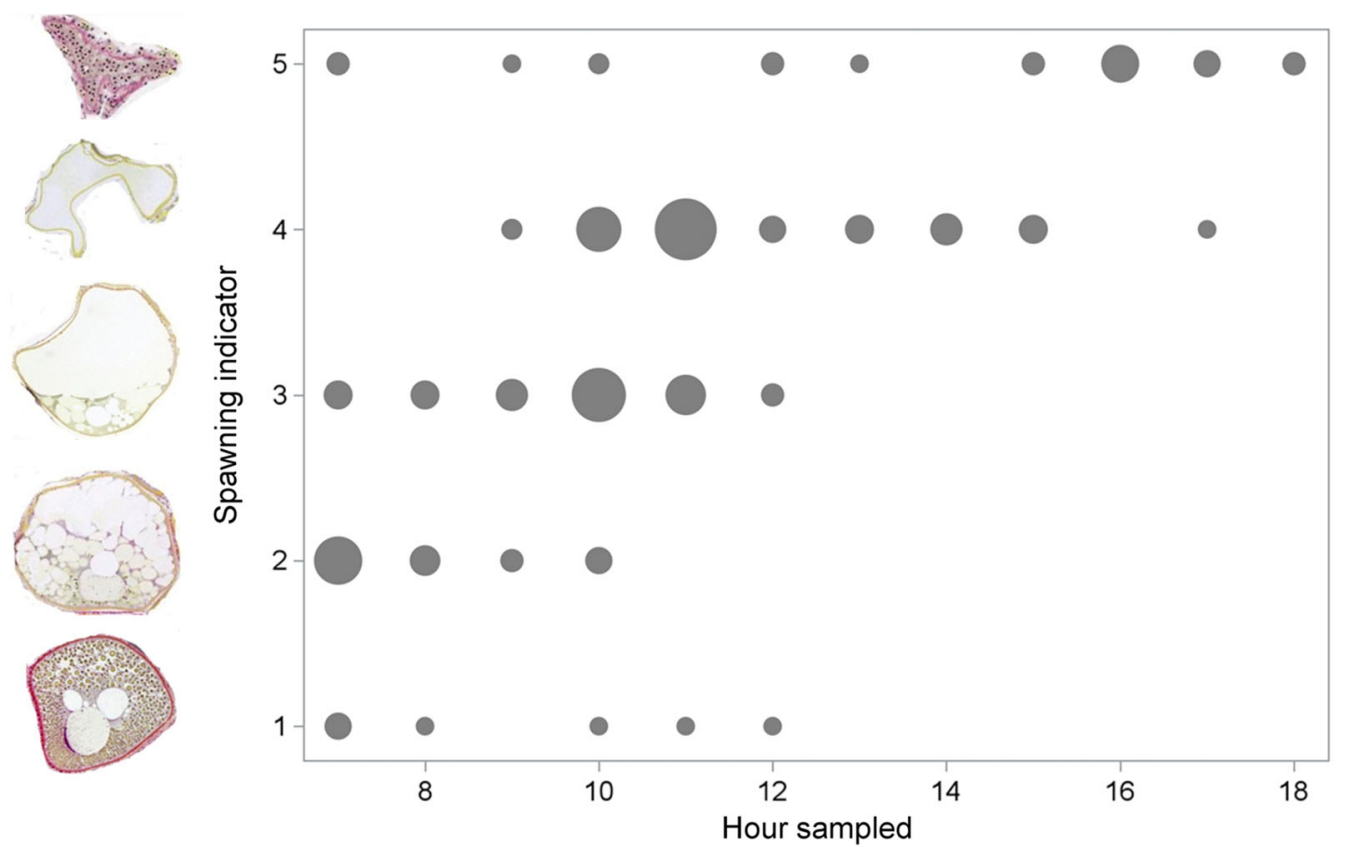

Fig. 5. Number of female red snapper Lutjanus campechanus with spawning indicators by hour sampled. Spawning indicators have representative images (left) and are as follows: (1) early germinal vesicle migration (GVM) with little yolk coalescence; (2) advanced GVM; (3) germinal vesicle breakdown; (4) hydrated or undergoing ovulation; and (5) newly-collapsed postovulatory follicles. Bubble size represents the number of females: the smallest bubble represents 1 fish and the largest bubble represents 36 fish with that indicator at that time

0.16 in April to a peak of 0.86 in June. In July, the proportion decreased to 0.65 , and by August it was 0.47. Although the temporal pattern of spawning activity with size was not statistically significant, large fish (>700 mm TL) demonstrated a more even distribution of spawning activity over the months of May (0.64), June (0.75), and July (0.63) than smaller fish.

\section{Fecundity and egg dry weight}

Larger females produced significantly more eggs per batch than smaller females (Fig. 9). Batch fecundities ranged from roughly 14000 to 4.2 million eggs female ${ }^{-1}$ and significantly increased with $\log _{\mathrm{e}}$-transformed TL $\left(\log _{\mathrm{e}}\right.$ batch fecundity $=-17.4+4.8 \log _{\mathrm{e}} \mathrm{TL}$; $\left.\mathrm{r}^{2}=0.68, \mathrm{n}=44\right)$ and $\log _{\mathrm{e}}$-transformed SW $\left(\log _{\mathrm{e}}\right.$ batch fecundity $=1.37+1.46 \log _{\mathrm{e}} \mathrm{SW} ; \mathrm{r}^{2}=0.63 \mathrm{n}=44$ ). The predictive batch fecundity relationship with $\log _{\mathrm{e}^{-}}$ transformed TL was improved by including sampling zone $\left(\mathrm{r}^{2}=0.75, \mathrm{p}=0.0019\right)$, but not age. Relative fecundity (eggs $\left.\mathrm{g}^{-1} \mathrm{SW}\right)$ also significantly increased with size (Kruskal Wallis, $\chi^{2}=9.0651, \mathrm{p}=0.0108, \mathrm{n}=$ $44)$. However, relative fecundity was highly variable (13 to 602 eggs g $^{-1} \mathrm{SW}$ ), with some females producing extremely small batches. Egg dry weight did not differ significantly with TL class (2-way ANOVA,
$\left.F_{1,25}=0.77, \mathrm{p}=0.6013\right)$ nor age (2-way ANOVA, $F_{1,25}=0.40, \mathrm{p}=0.8750$ ).

\section{Age truncation}

SA red snapper exhibit an extended potential reproductive lifespan of $49 \mathrm{yr}$. The maximum observed age of red snapper in this study was $21 \mathrm{yr}$, corresponding to a reproductive lifespan of $20 \mathrm{yr}$ or $43 \%$ of that estimated for a virgin stock. The maximum age at the $90 \%$ quantile at MSY was age 16, compared to $6 \mathrm{yr}$ old in this study, resulting in a current effective reproductive lifespan of $5 \mathrm{yr}$, which is only a third of that at MSY.

\section{DISCUSSION}

\section{Spatio-temporal spawning diversity}

Red snapper exhibited spawning activity over a wide range of sites, with a low proportion of active spawners and low number of females sampled per site. Although $75 \%$ of active spawners sampled in this study came from a relatively small area, additional spawning activity was observed over a much 

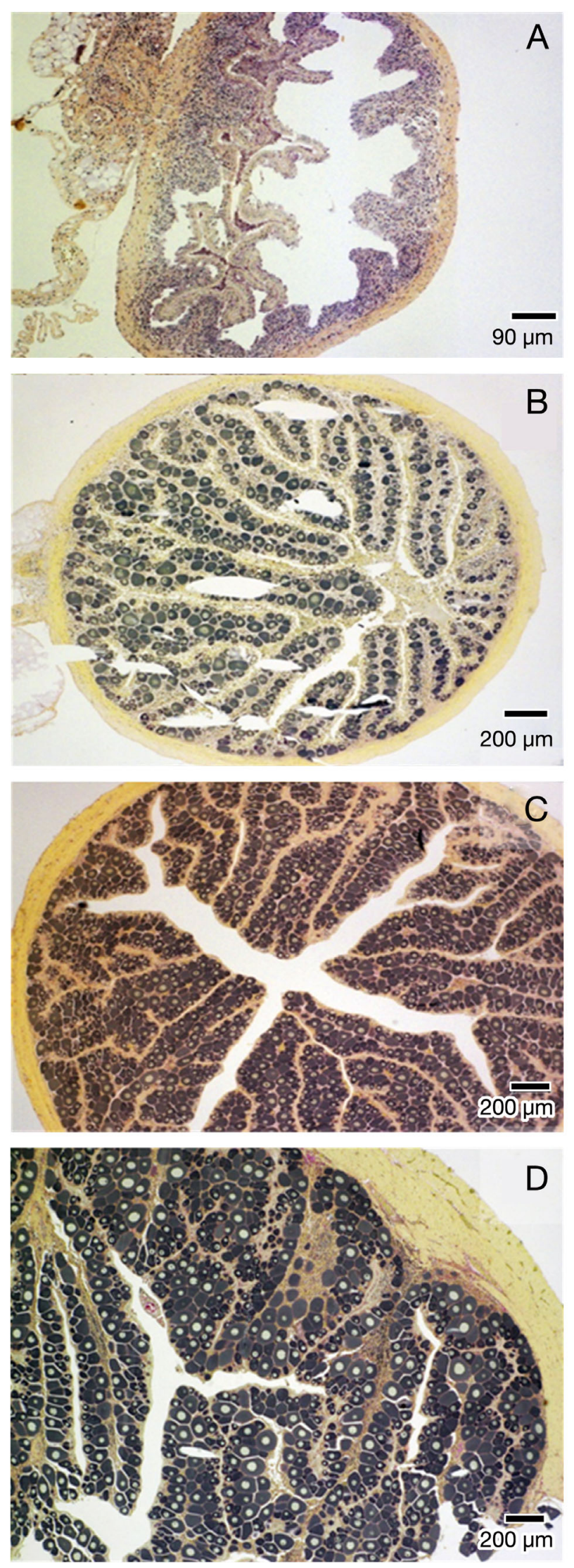

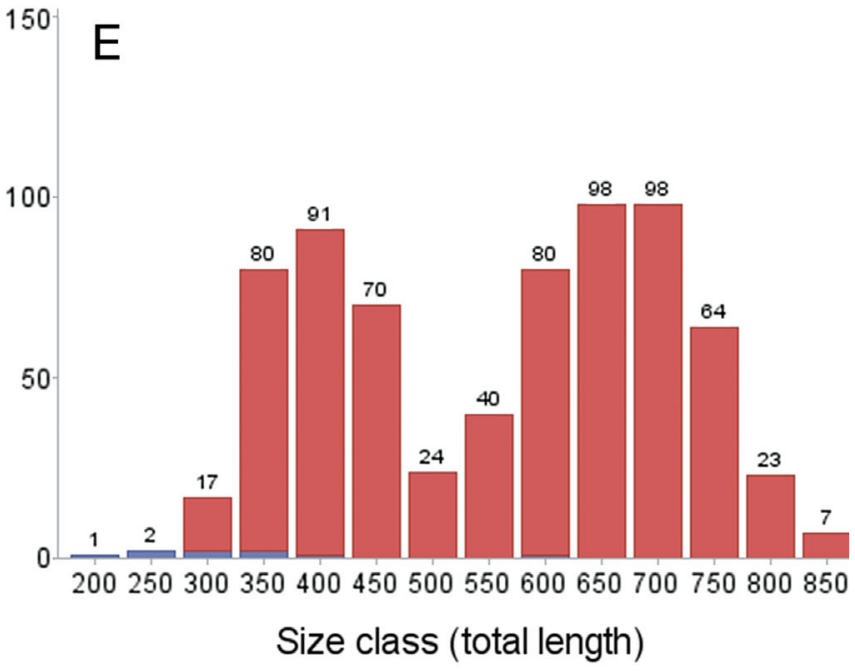

Fig. 6. Micrographs of red snapper Lutjanus campechanus ovaries. (A-C) Immature, with differing populations of primary growth oocytes; (D) mature and regenerating. Note the larger size of the cross section and more disorganized lamellae. (E) Size distribution of immature (blue) and mature females (red) with sample size indicated above each bar

larger area and wide range of depths. In addition, red snapper exhibited an extended spawning season and wide range of spawn times. These results suggest that red snapper spawn in key areas but can also spawn in a range of habitats and time, resulting in a spatio-temporal buffer to disturbance. In addition, the relatively low number of females and proportion of actively spawning individuals, even within the concentrated spawning area, suggests that red snapper do not form large spawning aggregations as seen in many reef fish and other snappers (Claydon 2004, Sadovy de Mitcheson et al. 2013).

However, gear bias could affect our results if the capture of fish at a given site affected the probability of later catches (i.e. the bite can turn off) or the probability of sampling hydrated females. A decrease in capture with hook and line could occur if females feed less due to hydration and consequent lack of body cavity space, or if a species does not feed during the spawning season, e.g. Atlantic cod (Fordham \& Trippel 1993). Red snapper clearly fed while spawning given that roughly a third of the females sampled were hydrated, and in fact hydrated females were sampled almost twice as frequently $(32.7 \%)$ as females with Day 1 POFs (17.6\%). Thus, if the sampling sites corresponded to spawning sites and fish left these areas after spawning, potentially there was sampling bias in favor of hydrated females but there does not appear to be gear bias due to decreased 


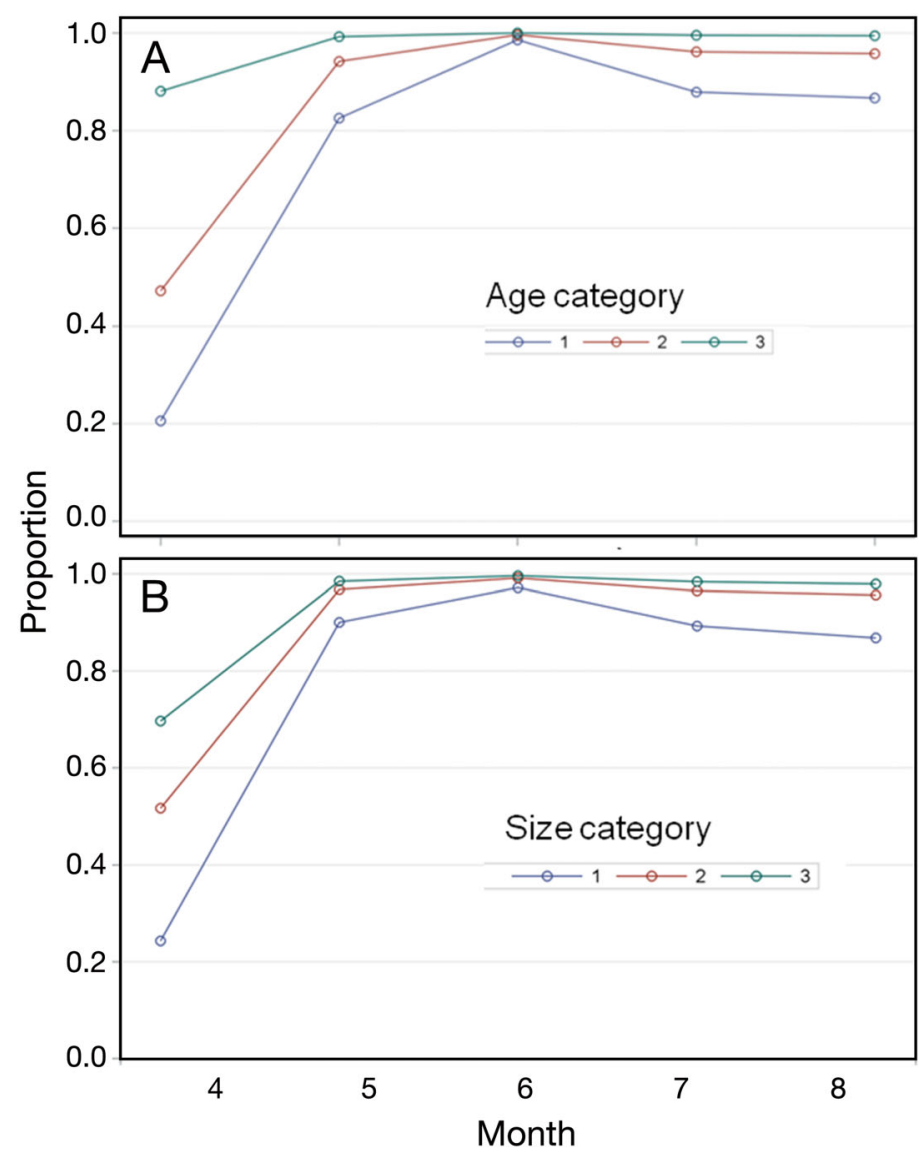

Fig. 7. Proportion of female red snapper Lutjanus campechanus in the spawning population by month and (A) by age category, where $1=$ young $(<4 \mathrm{yr}), 2=$ middle $(4$ and $5 \mathrm{yr})$, and $3=$ older $(>5 \mathrm{yr})$; and (B) by size category, where $1=$ small $(<500 \mathrm{~mm}$ total length, TL), $2=$ medium $(500-700 \mathrm{~mm}$ $\mathrm{TL})$, and $3=$ large $(>700 \mathrm{~mm} \mathrm{TL})$

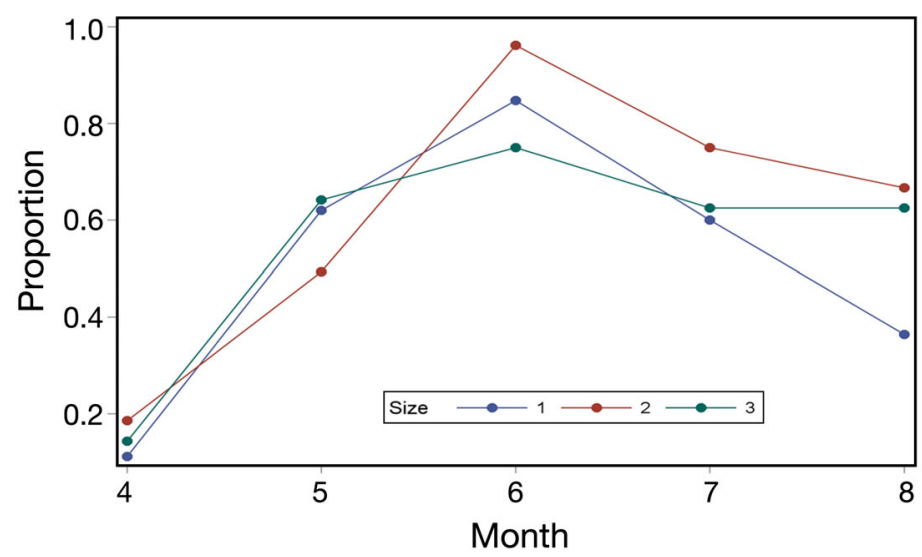

Fig. 8. Size-specific spawning fractions of red snapper Lutjanus campechanus by month. Size classes are $1=$ small ( $<500 \mathrm{~mm}$ total length, TL), $2=$ medium $(500-700 \mathrm{~mm}$ TL), and $3=$ large $(>700 \mathrm{~mm} \mathrm{TL})$

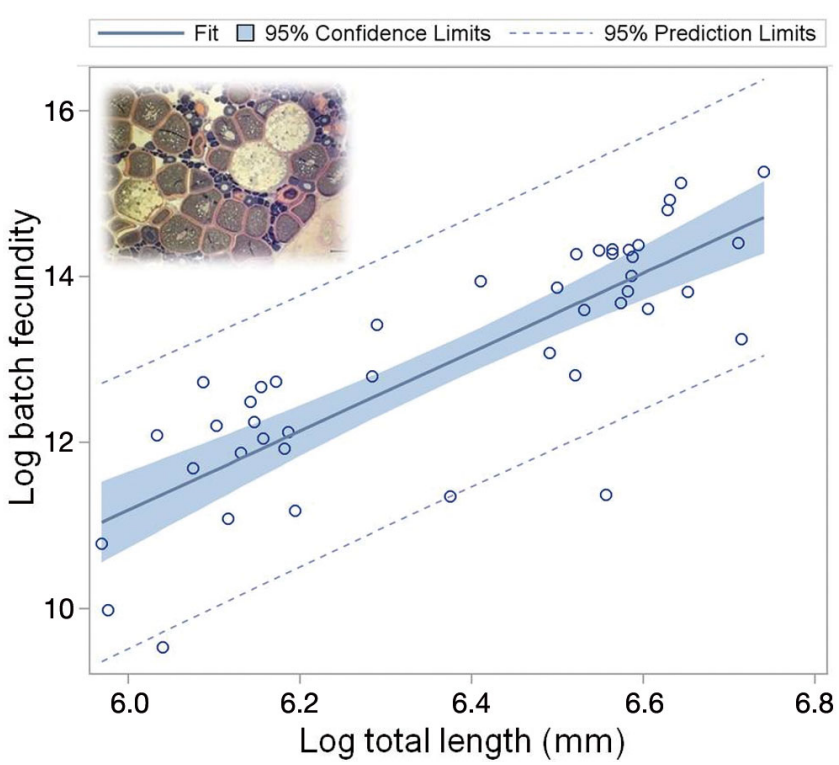

Fig. 9. Distribution of red snapper Lutjanus campechanus batch fecundity estimates by size class (based on total length in $100 \mathrm{~mm}$ increments). Although batch fecundities were highly variable, there was a significant relationship with size. Fish were capable of recruiting very small batches as can be seen by the isolated hydrating oocytes (light gray) in this micrograph. No fish smaller than $600 \mathrm{~mm}$ total length had batch fecundities greater than 1 million

feeding. However, it was not possible to assess how well our sampling indicated spawning site density, and there is a need for further research integrating other methods to assess this (Saul et al. 2013). In addition, the lower sampling effort in September and October could have affected results, if fish shifted their distribution during these months.

Fish species differ in the temporal and spatial predictability of aggregation behavior, with population declines most commonly associated with those species which form few aggregations of large numbers over relatively short time periods (Sadovy De Mitcheson et al. 2008). The decreased reproductive resilience associated with this reproductive strategy is due to both ecological and fishery factors. As an ecological example, climate change can cause a disconnect between the timing and location associated with reproductive success, decreasing productivity (Rijnsdorp et al. 2009), whereas from a fisheries perspective, reproductive behavior can impact catchability (Villegas-Ríos et al. 2014), with species forming large spawning aggregations at predictable locations and times being more vulnerable to overfishing (Erisman et al. 2012).

Little is known about the cues used for spawning site selection, but the following hypotheses have 
been suggested: natal homing, learned behavior through 'spawning groups' formed at first maturity, or following the behavior of older fish (Colin 1996, Thorrold et al. 2001, Claydon et al. 2012). Some reef fish use deeper habitat as they age (Collins \& McBride 2011). However, for the ages we were able to assess, this pattern was not apparent for SA red snapper. The occurrence of some sites with 100\% actively spawning females in this study, however, suggests that even if spawning groups are small, red snapper may move to some sites specifically to spawn, but further research is needed to confirm this. An additional factor in understanding how spatial diversity affects reproductive resilience is spawning site fidelity (Adams et al. 2009, Bijoux et al. 2013) and the role it may play in potential site-specific differences in productivity (Lowerre-Barbieri et al. 2013, 2014). Although red snapper have been reported to exhibit high site fidelity in the Gulf of Mexico at artificial reefs (Szedlmayer \& Schroepfer 2005), there is no published data on spawning site fidelity or movements associated with spawning.

\section{Maturity}

Sexual maturity occurs at the lifetime scale and is a critical component of population dynamics and life history theory (Stearns 1992). In this study, we were unable to collect representative samples of immature and mature fish and could not estimate traditional size- or age-at-50\% maturity. However, we were able to show that red snapper recruited to the spawning population at a small size (minimum: $310 \mathrm{~mm}$ TL) and young age (94\% of 2 yr olds were mature). These results of early maturation are similar to past results (White \& Palmer 2004) and for red snapper in the Gulf of Mexico (Woods et al. 2003). Such early maturation in a species which lives to $50 \mathrm{yr}$ or older is unexpected (SEDAR24 2010). Other species of reef fish inhabiting the southeastern region of the US exhibit either lower longevity or higher age at maturity. For example, the vermilion snapper Rhomboplites aurorubens matures at age 1 (Hood \& Johnson 1999) but has a maximum observed age of $26 \mathrm{yr}$ (Allman 2007). The red grouper Epinephelus morio matures at age 2 and lives to approximately $20 \mathrm{yr}$ (SEDAR19 2010) and the mutton snapper Lutjanis analis, which matures at approximately $4 \mathrm{yr}$ old, lives to age $40 \mathrm{yr}$ (SEDAR15A 2008). Red snapper in our study matured earlier than the mean reported age at maturity for lutjanids of $3.5 \mathrm{yr}$ and exhibited a much longer potential reproductive lifespan (45 to
$49 \mathrm{yr}$ ) compared to the mean for lutjanids of $11.7 \mathrm{yr}$ (Martinez-Andrade 2003).

However, due to a lack of historic maturity estimates for this stock, it cannot be confirmed whether the early maturation is a result of overfishing, as has been seen in other species (Jørgensen et al. 2007, Audzijonyte et al. 2013, Marty et al. 2014), or simply a very resilient reproductive strategy. If this early maturation is due to 'fisheries-induced adaptive change' (Heino et al. 2013), it could have important implications for fisheries management. The concern in terms of productivity with a shift towards earlier maturation is that this would lead to slower growth due either to the principle of allocation (i.e. energy allocated earlier to reproduction would mean less energy left over for growth; Stearns 1992) or associated selection for slower growth. If slower growth is selected for, this change in productivity would not be easily reversed (Law \& Grey 1989, Kraak 2007, Thorpe 2007).

\section{Demographic trends in reproductive timing}

Reproductive timing can be affected by overexploitation and age truncation at multiple temporal scales. At the annual and interannual scales, age truncation can affect the duration of the spawning season (Anderson et al. 2008, Pecquerie et al. 2009, Wright \& Trippel 2009) and spawning frequency (Fitzhugh et al. 2012, Cooper et al. 2013). In this study, although some individual spawning was identified from April through September, recruitment to the spawning population and spawning activity peaked in June. Larger fish, however, distributed their spawning activity more evenly over multiple months. In piscivorous species with an income breeder/ batch spawning reproductive strategy, larger individuals are expected to exhibit this pattern because of their increased foraging ability within the spawning season. Restricted spawning seasonality can result in decreased resilience of fish populations to environmental conditions and exploitation (Hsieh et al. 2008, Wright \& Trippel 2009), as the bet-hedging strategy which evolved to overcome a variable environment and produce reproductive success has been compromised (Hsieh et al. 2010).

\section{Fecundity and egg quality}

Red snapper, similar to other pelagic spawners, exhibited a significant relationship between batch 
fecundity and size, but the relationship was not improved by the inclusion of age as an explanatory variable. It did, however, improve with the inclusion of sampling zone, reflecting the smaller size distribution of fish sampled in the most southern zone. Although this is not commonly done, the batch fecundity to size relationship can be used as a metric to understand the importance of the BOFFFF effect. For example, comparing the $\log _{\mathrm{e}}$-transformed batch fecundity to SW relationship of red snapper in this study to another batch spawner with indeterminate fecundity, the spotted seatrout Cynoscion nebulosus (Lowerre-Barbieri et al. 2009), it can be seen that the steepness of the slope for red snapper (1.46) is greater than that for spotted seatrout (1.23) but the fit is weaker $\left(r^{2}=0.63\right.$ compared to $\left.r^{2}=0.72\right)$. The relatively poor fit with red snapper reflects the wide range of batch sizes and this species' capability of mobilizing very small batches of eggs. Similar variability in red snapper batch fecundity has been previously reported, with relative fecundity ranging from $235 \pm 56$ eggs per gram SW off the east coast of Florida to $27 \pm 11$ eggs per gram SW from the Dry Tortugas (Brown-Peterson et al. 2009). The ability of red snapper to mobilize small batches may allow them to spawn even when they have relatively low energy reserves.

\section{Reproductive resilience}

There is growing awareness that stock productivity can change over time for reasons not associated with abundance or SSB (Vert-pre et al. 2013). The SA red snapper stock has exhibited highly variable recruitment, as well as strong year classes being produced in years with low SSB (SEDAR24 2010), indicating resilience based on the traditional measure of steepness. However, the SA red snapper stock has also undergone fairly extensive age truncation (SEDAR24 2010), and the effects of size and age on reproductive potential are increasingly recognized as important to stock productivity (Berkeley et al. 2004, Hsieh et al. 2010, Hixon et al. 2014). We estimated the potential reproductive lifespan of red snapper to be $49 \mathrm{yr}$. However, it is difficult to estimate life history parameters in a heavily fished stock and apply them to a virgin stock, and estimates of maximum age, of course, depend on sample size (Hoenig 1983). Thus, if maturation has decreased due to overfishing, a more realistic estimate of potential reproductive lifespan would be 45 to 46 yr. Given that very few fish over the age of 20 yr have been observed in this stock throughout its range (SEDAR24 2010), we feel that using the maximum age observed in our study, $21 \mathrm{yr}$, was appropriate to estimate the observed reproductive lifespan and indicated an approximate $50 \%$ loss in reproductive life span. However, using the maximum age at the $90 \%$ quantile removes the problem of defining reproductive lifespan on extremely rare events (i.e. the capture of old fish in an over-exploited stock). Using this metric, the current effective reproductive lifespan was only a third of that predicted at MSY, suggesting a high degree of age truncation. Because age truncation can lead to regime shifts and reduced productivity (Anderson et al. 2008, Heino et al. 2013), we feel this is concerning. It also makes it difficult to fully assess the BOFFFF effect, as reproductive traits such as egg dry weights (used as a proxy for egg quality), spawning fraction, or spawning habitat, in fact could have demographic trends in a population with a more extended age distribution.

\section{CONCLUSIONS}

Our understanding of how fishing impacts populations is changing, as evidenced by a paradigm shift from single-species to ecosystem-based approaches (Walters \& Martell 2004, Francis et al. 2007), a concurrent shift from an equilibrium perspective to a resilience perspective (Hughes et al. 2005), and increased research on population productivity and persistence in the face of climate change (Rijnsdorp et al. 2009). Reproductive resilience is emerging as a new conceptual model to assess the impacts of climate change on productivity in diverse species, such as arctic birds (Martin \& Wiebe 2004), lemurs (Canale et al. 2012), and palm trees (Montúfar et al. 2011). In this study, we have integrated emerging understanding of reproductive processes, both in terms of spatio-temporal reproductive behavior and demographic effects (or the BOFFFF effect) with this concept to help quantify expected reproductive resilience to fishing. Many of the parameters estimated in this study are common to reproductive studies, but are not always quantified in a way that can be used to compare reproductive components over space, time, or between species. Thus, we have drawn from life history theory, population dynamics, and current stock assessments to present ways to quantify spatio-temporal reproductive diversity, reproductive lifespan erosion, and demographic effects in reproductive output. However, the metrics we present and reproductive traits evaluated are by no means comprehensive, and we hope that future studies will improve upon them. 
Acknowledgements. We thank Russ Brodie, Doug Adams, Justin Solomon, and other FWRI field staff for their contributions to field collections. We also thank Jessica Carroll and the age and growth lab personnel for aging these fish, as well as 3 anonymous reviewers and the editor, Stylianos Somarakis, for helpful insights which improved this article. Lastly, we thank Kyle Shertzer and John Carmichael for providing the expected age distribution at MSY and the map of the SA red snapper management zone. This work was supported by NOAA CRP Grants NA11NMF4540116 and Grant F-59 from the US Fish and Wildlife Service Sport Fish Restoration program. However, the views and conclusions are those of the author(s) and do not necessarily reflect the opinions or policies of the US government or any of its agencies.

\section{LITERATURE CITED}

Adams A, Wolfe RK, Barkowski N, Overcash D (2009) Fidelity to spawning grounds by a catadromous fish, Centropomus undecimalis. Mar Ecol Prog Ser 389: 213-222

> Allman RJ (2007) Small-scale spatial variation in the population structure of vermilion snapper (Rhomboplites aurorubens) from the northeast Gulf of Mexico. Fish Res 88: 88-99

> Anderson CNK, Hsieh C, Sandin SA, Hewiit R and others (2008) Why fishing magnifies fluctuations in fish abundance. Nature 452:835-839

Audzijonyte A, Kuparinen A, Fulton EA (2013) How fast is fisheries-induced evolution? Quantitative analysis of modelling and empirical studies. Evol Appl 6:585-595

Begg GA, Marteinsdottir G (2002) Environmental and stock effects on spawning origins and recruitment of cod Gadus morhua. Mar Ecol Prog Ser 229:263-277

Berkeley SA, Hixon MA, Larson RJ, Love MS (2004) Fisheries sustainability via protection of age structure and spatial distribution of fish populations. Fisheries 29:23-32

Bijoux JP, Dagorn L, Berke G, Cowley PD, Soria M, Gaertner JC, Robinson J (2013) Temporal dynamics, residency and site fidelity of spawning aggregations of a herbivorous tropical reef fish Siganus sutor. Mar Ecol Prog Ser 475: 233-247

Brown-Peterson NJ, Burns KM, Overstreet RM (2009) Regional differences in Florida red snapper reproduction. In: Proc 61st Gulf Caribb Fish Inst, 10-14 Nov, 2008, Gosier, Guadeloupe, French West Indies

Brown-Peterson N, Wyanski D, Saborido-Rey F, Macewicz B, Lowerre-Barbieri S (2011) A standardized terminology for describing reproductive development in fishes. Mar Coast Fish Dyn Manag Ecosyst Sci 3:52-70

Brulé T, Colás-Marrufo T, Pérez-Díaz E, Sámano-Zapata JC (2010) Red snapper reproductive biology in the southern Gulf of Mexico. Trans Am Fish Soc 139:957-968

Canale CI, Huchard E, Perret M, Henry PY (2012) Reproductive resilience to food shortage in a small heterothermic primate. PLoS ONE 7:e41477

Claydon J (2004) Spawning aggregations of coral reef fishes: characteristics, hypotheses, threats and management. Mar Biol Annu Rev 42:265-302

> Claydon JAB, McCormick MI, Jones GP (2012) Patterns of migration between feeding and spawning sites in a coral reef surgeonfish. Coral Reefs 31:77-87

Colin PL (1996) Longevity of some coral reef fish spawning aggregations. Copeia 1996:189-192
Collins AB, McBride RS (2011) Demographics by depth: spatially explicit life-history dynamics of a protogynous reef fish. Fish Bull 109:232-242

Collins LA, Johnson AG, Keim CP (1996) Spawning and annual fecundity of the red snapper (Lutjanus campechanus) from the northeastern Gulf of Mexico. In: Arreguin-Sanchez F, Munro JL, Balgos MC, Pauly D (eds) Biology, fisheries and culture of tropical groupers and snappers. ICLARM Conference Proceedings, Number 48, p 174-188

Cooper WT, Barbieri LR, Murphy MD, Lowerre-Barbieri SK (2013) Assessing stock reproductive potential in species with indeterminate fecundity: effects of age truncation and size-dependent reproductive timing. Fish Res 138: $31-41$

Cowan JH Jr (2011) Red snapper in the Gulf of Mexico and US South Atlantic: data, doubt, and debate. Fisheries 36: 319-331

Erisman B, Aburto-Oropeza O, Gonzalez-Abraham C, Mascarenas-Osorio I, Moreno-Baez M, Hastings PA (2012) Spatio-temporal dynamics of a fish spawning aggregation and its fishery in the Gulf of California. Sci Rep 2:284

Fitzhugh GR, Shertzer KW, Kellison GT, Wyanski DM (2012) Review of size- and age-dependence in batch spawning: implications for stock assessment of fish species exhibiting indeterminate fecundity. Fish Bull 110:413-425

Folke C (2006) Resilience: the emergence of a perspective for social-ecological systems analyses. Glob Environ Change 16:253-267

Fordham SE, Trippel EA (1999) Feeding behaviour of cod Gadus morhua in relation to spawning. J Appl Ichthyol 15:1-9

- Francis RC, Hixon MA, Clarke ME, Murawski SA, Ralston S (2007) Ten commandments for ecosystem-based fisheries scientists. Fisheries 32:217-233

Garrod D, Horwood J (1984) Reproductive strategies and the response to exploitation. In: Potts GW, Wootton RJ (eds) Fish reproduction. Academic Press, New York, NY, p 367-384

Haslob H, Rabade-Uberos S, Saborido-Rey F (2013) Seasonal variability of fecundity and spawning dynamics of Baltic sprat. Fish Res 138:99-109

Healey MC (2009) Resilient salmon, resilient fisheries for British Columbia, Canada. Ecol Soc 14:2

Heino M, Baulier L, Boukal DS, Ernande B and others (2013) Can fisheries-induced evolution shift reference points for fisheries management? ICES J Mar Sci 70:707-721

Hixon MA, Johnson DW, Sogard SM (2014) BOFFFFs: on the importance of conserving old-growth age structure in fishery populations. ICES J Mar Sci 71:2171-2185

Hoenig JM (1983) Empirical use of longevity data to estimate mortality rates. Fish Bull 81:898-902

Hood PB, Johnson AK (1999) Age, growth, mortality, and reproduction of vermilion snapper, Rhomboplites aurorubens, from the eastern Gulf of Mexico. Fish Bull 97: $828-841$

> Hsieh CH, Reiss CS, Hewitt RP, Sugihara G (2008) Spatial analysis shows that fishing enhances the climatic sensitivity of marine fishes. Can J Fish Aquat Sci 65:947-961

$>$ Hsieh CH, Yamauchi A, Nakazawa T, Wang WF (2010) Fishing effects on age and spatial structures undermine population stability of fishes. Aquat Sci 72:165-178

> Hughes TP, Bellwood DR, Folke C, Steneck RS, Wilson J (2005) New paradigms for supporting the resilience of marine ecosystems. Trends Ecol Evol 20:380-386 
Hunter JR, Macewicz BJ (1985) Measurement of spawning frequency in multiple spawning fishes. In: Lasker R (ed) An egg production method for estimating spawning biomass of pelagic fish: application to the northern anchovy, Engraulis mordax. NOAA Tech Rep NMFS 36. US Department of Commerce, NOAA, NMFS, p 79-94

Hunter JR, Lo NC, Leong RJ (1985) Batch fecundity in multiple spawning fishes. In: Lasker R (ed) An egg production method for estimating spawning biomass of pelagic fish: application to the northern anchovy, Engraulis mordax. NOAA Tech Rep NMFS 36. US Department of Commerce, NOAA, NMFS, p 67-78

> Jackson MW, Nieland DL, Cowan JH (2006) Diel spawning periodicity of red snapper Lutjanus campechanus in the northern Gulf of Mexico. J Fish Biol 68:695-706

> Jalabert B (2005) Particularities of reproduction and oogenesis in teleost fish compared to mammals. Reprod Nutr Dev 45:261-279

Jearld A Jr (1983) Age determination. In: Nielsen LA, Johnson DL (eds) Fisheries techniques. American Fisheries Society, Bethesda, MD, p 301-324

> Jensen AL (1996) Beverton and Holt life history invariants result from optimal trade-off of reproduction and survival. Can J Fish Aquat Sci 53:820-822

$>$ Jørgensen C, Ernande B, Fiksen Ø, Dieckmann U (2006) The logic of skipped spawning in fish. Can J Fish Aquat Sci 63:200-211

> Jørgensen C, Enberg K, Dunlop ES, Arlinghaus R and others (2007) Managing evolving fish stocks. Science 318: 1247-1248

Kamler E (2005) Parent-egg-progeny relationships in teleost fishes: an energetics perspective. Rev Fish Biol Fish 15: 399-421

Kraak SBM (2007) Does the probabilistic maturation reaction norm approach disentangle phenotypic plasticity from genetic change? Mar Ecol Prog Ser 335:295-300

Law R, Grey D (1989) Evolution of yields from populations with age-specific cropping. Evol Ecol 3:343-359

Lowerre-Barbieri SK (2009) Reproduction in relation to conservation and exploitation of marine fishes. In: Jamieson BGM (ed) Reproductive biology and phylogeny of fishes (agnathans and bony fishes). Science Publishers, Enfield, NH, p 371-394

Lowerre-Barbieri SK, Barbieri LR (1993) A new method of oocyte separation and preservation for fish reproduction studies. Fish Bull 91:165-170

Lowerre-Barbieri SK, Henderson N, Llopiz J, Walters S, Bickford J, Muller R (2009) Defining a spawning population (spotted seatrout Cynoscion nebulosus) over temporal, spatial, and demographic scales. Mar Ecol Prog Ser 394:231-245

Lowerre-Barbieri S, Brown-Peterson N, Murua H, Tomkiewicz J, Wyanski D, Saborido-Rey F (2011a) Emerging issues and methodological advances in fisheries reproductive biology. Mar Coast Fish Dyn Manag Ecosyst Sci 3:32-51

Lowerre-Barbieri S, Ganias K, Saborido-Rey F, Murua H, Hunter J (2011b) Reproductive timing in marine fishes: variability, temporal scales, and methods. Mar Coast Fish Dyn Manag Ecosyst Sci 3:71-91

> Lowerre-Barbieri SK, Walters S, Bickford J, Cooper W, Muller R (2013) Site fidelity and reproductive timing at a spotted seatrout spawning aggregation site: individual versus population scale behavior. Mar Ecol Prog Ser 481: 181-197
Lowerre-Barbieri S, Villegas-Ríos D, Walters S, Bickford J, Cooper W, Muller R (2014) Spawning site selection and contingent behavior in common snook, Centropomus undecimalis. PLoS ONE 9:e101809

Mangel M, MacCall AD, Brodziak J, Dick EJ and others (2013) A perspective on steepness, reference points, and stock assessment. Can J Fish Aquat Sci 70:930-940

Martin K, Wiebe KL (2004) Coping mechanisms of alpine and arctic breeding birds: extreme weather and limitations to reproductive resilience. Integr Comp Biol 44: 177-185

Martinez-Andrade F (2003) A comparison of life histories and ecological aspects among snappers (Pisces: Lutjanidae). PhD dissertation, Louisiana State University and Agricultural and Mechanical College, Baton Rouge, LA

Marty L, Rochet MJ, Ernande B (2014) Temporal trends in age and size at maturation of four North Sea gadid species: cod, haddock, whiting and Norway pout. Mar Ecol Prog Ser 497:179-197

Montúfar R, Anthelme F, Pintaud JC, Balslev H (2011) Disturbance and resilience in tropical American palm populations and communities. Bot Rev 77:426-461

Murua H, Saborido-Rey F (2003) Female reproductive strategies of marine fish species of the North Atlantic. J Northwest Atl Fish Sci 33:23-31

> Murua H, Kraus G, Saborido-Rey F, Witthames PR, Thorsen A, Junquera S (2003) Procedures to estimate fecundity of marine fish species in relation to their reproductive strategy. J Northwest Atl Fish Sci 33:33-54

Myers RA, Bowen KG, Barrowman NJ (1999) Maximum reproductive rate of fish at low population sizes. Can J Fish Aquat Sci 56:2404-2419

Pecquerie L, Petitgas P, Kooijman S (2009) Modeling fish growth and reproduction in the context of the Dynamic Energy Budget theory to predict environmental impact on anchovy spawning duration. J Sea Res 62:93-105

> Quintero-Hunter I, Grier H, Muscato M (1991) Enhancement of histological detail using metanil yellow as counterstain in periodic acid Schiff's hematoxylin staining of glycol methacrylate tissue sections. Biotech Histochem 66:169-172

Rideout RM, Tomkiewicz J (2011) Skipped spawning in fishes: more common than you might think. Mar Coast Fish Dyn Manag Ecosyst Sci 3:176-189

> Rijnsdorp AD, Peck MA, Engelhard GH, Mollmann C, Pinnegar JK (2009) Resolving the effect of climate change on fish populations. ICES J Mar Sci 66:1570-1583

Rose KA, Cowan JH, Winemiller KO, Myers RA, Hilborn R (2001) Compensatory density dependence in fish populations: importance, controversy, understanding and prognosis. Fish Fish 2:293-327

Rowe S, Hutchings JA (2003) Mating systems and the conservation of commercially exploited marine fish. Trends Ecol Evol 18:567-572

> Sadovy Y (2001) The threat of fishing to highly fecund fishes. J Fish Biol 59:90-108

Sadovy De Mitcheson Y, Cornish A, Domeier M, Colin PL, Russell M, Lindeman KC (2008) A global baseline for spawning aggregations of reef fishes. Conserv Biol 22: 1233-1244

Sadovy de Mitcheson Y, Craig MT, Bertoncini AA, Carpenter KE and others (2013) Fishing groupers towards extinction: a global assessment of threats and extinction risks in a billion dollar fishery. Fish Fish 14:119-136 
Saul SE, Walter JF, Die DJ, Naar DF, Donahue BT (2013) Modeling the spatial distribution of commercially important reef fishes on the West Florida Shelf. Fish Res 143: $12-20$

Scott BE, Marteinsdottir G, Begg GA, Wright PJ, Kjesbu OS (2006) Effects of population size/age structure, condition and temporal dynamics of spawning on reproductive output in Atlantic cod (Gadus morhua). Ecol Model 191: $383-415$

SEDAR (SouthEast Data and Assessment Review)15A (2008) Stock Assessment Report 3 (SAR 3): South Atlantic and Gulf of Mexico Mutton Snapper. SEDAR, NMFS, North Charleston, SC

SEDAR19 (2010) Stock Assessment Report: South Atlantic Red Grouper. SEDAR, NMFS, North Charleston, SC

SEDAR24 (2010) Stock Assessment Report: South Atlantic Red Snapper. SEDAR, NMFS, North Charleston, SC

Stearns SC (1992) The evolution of life histories. Oxford University Press, New York, NY

Szedlmayer ST, Schroepfer RL (2005) Long-term residence of red snapper on artificial reefs in the Northeastern Gulf of Mexico. Trans Am Fish Soc 134:315-325

Thorpe JE (2007) Maturation responses of salmonids to changing developmental opportunities. Mar Ecol Prog Ser 335:285-288

Thorrold SR, Latkoczy C, Swart PK, Jones CM (2001) Natal homing in a marine fish metapopulation. Science 291: 297-299

Editorial responsibility: Stylianos Somarakis, Heraklion, Greece
Vert-pre KA, Amoroso RO, Jensen OP, Hilborn R (2013) Frequency and intensity of productivity regime shifts in marine fish stocks. Proc Natl Acad Sci USA 110: 1779-1784

Villegas-Ríos D, Alós J, Palmer M, Lowerre-Barbieri SK, Bañón R, Alonso-Fernández A, Saborido-Rey F (2014) Life-history and activity shape catchability in a sedentary fish. Mar Ecol Prog Ser 515:239-250

Walker B, Holling CS, Carpenter SR, Kinzig A (2004) Resilience, adaptability and transformability in social-ecological systems. Ecol Soc 9:5

Walters CJ, Martell SJD (2004) Fisheries ecology and management. Princeton University Press, Princeton, NJ

White DB, Palmer SM (2004) Age, growth, and reproduction of the red snapper, Lutjanus campechanus, from the Atlantic waters of the southeastern U.S. Bull Mar Sci 75: 335-360

Woods MK, Fischer AJ, Cowan J Jr, Nieland D (2003) Size and age at maturity of female red snapper Lutjanus campechanus in the northern Gulf of Mexico. Proc Gulf Carib Fish Inst 54:526-537

> Wright PJ, Trippel EA (2009) Fishery-induced demographic changes in the timing of spawning: consequences for reproductive success. Fish Fish 10:283-304

> Young JL, Bornik ZB, Marcotte ML, Charlie KN, Wagner GN, Hinch SG, Cooke SJ (2006) Integrating physiology and life history to improve fisheries management and conservation. Fish Fish 7:262-283

Submitted: October 16, 2014; Accepted: January 21, 2015 Proofs received from author(s): March 26, 2015 